\title{
Monitoring of Ulva prolifera blooms in the Yellow Sea with MODIS
}

\author{
Hongyuan Zhang ${ }^{1,2}$, Qing $\mathrm{Xu}^{1,2^{*}}$, Yongcun Cheng ${ }^{3}$, \\ Meixiang Chen ${ }^{1,2}$, Juncheng Zuo ${ }^{1,2}$ \\ 1. Key Laboratory of Coastal Disaster and Defence, Ministry of \\ Education, Hohai University, Nanjing, China
}

\author{
2. College of Harbor, Coastal and Offshore Engineering \\ Hohai University, Nanjing, China \\ 3. National Space Institute, Technical University of Denmark, \\ Copenhagen, Denmark \\ *Corresponding author: maggiexu@hhu.edu.cn
}

\begin{abstract}
In this paper, the occurrence and distribution of Ulva prolifera bloom in the Yellow Sea in summer of 2008 are investigated using the medium-resolution data from operational MODIS (Moderate Resolution Imaging Spectroradiometer) instruments onboard Terra and Aqua satellites with an FAI(Floating Algae Index) method. The sea surface wind fields from NASA's QuikSCAT (Quick Scatterometer) are also analyzed to study their impact on the movement of the floating macroalgae.
\end{abstract}

Index Terms-Ulva prolifera, MODIS, FAI, the Yellow Sea

\section{INTRODUCTION}

A bloom of Ulva prolifera (previously known as Enteromorpha prolifera), a type of green macroalgae, occurred in the Yellow Sea in mid May, 2008. It lasted for about two months and accumulated along the coast of Qingdao, host city for Olympic sailing game, which resulted in the largest "green tide" event in history ${ }^{[1]}$. Some scientists ${ }^{[1,2]}$ attributed the cause of the bloom to the expansion of coastal Porphyra yezoensis seaweed aquaculture along the shoreline of Subei Bank north of the Yangtze River mouth. The algae bloom was non-toxic but can lead to ecological consequences and cause economic losses to marine industries. In particular, it brought great environmental pressure on the Olympic sailing event in this case. Thus it is necessary to monitor the occurrence and movement of $U$. prolifera bloom.

In this work we use satellite MODIS data from May to July 2008 to investigate the location and extent of $U$. prolifera bloom. In the Yellow Sea, the summer surface currents are primarily wind driven ${ }^{[3]}$. By combining the sea surface wind data from QuikSCAT, the influence of the wind on the evolution of the bloom is also examined.

\section{DATA AND METHODOLOGY}

\section{DATA}

Here the MODIS images with high spatial resolution $(250 \mathrm{~m}$ and $500 \mathrm{~m}$ ) are used to analyze location and extent of the $U$. prolifera bloom. The MODIS instruments are onboard two satellites, Terra and Aqua, respectively, which could provide four images one day for the same region. With high spatial and temporal resolution, MODIS data are widely used in oceanic research ${ }^{[4]}$. They are of great significance on the monitoring of red and green tides all over the world ocean due to their capability in observing the ocean color $^{[1,2,5 \sim 7]}$.

Daily MODIS images were searched for the Yellow Sea from 1 May to 31 July in 2008. About 11 images sufficiently cloud free were obtained which show the existence of floating patches of algae. Fig. 1 is an example of MODIS image on 31 May, 2008, on which the $U$. prolifera are clearly shown as large green patches.

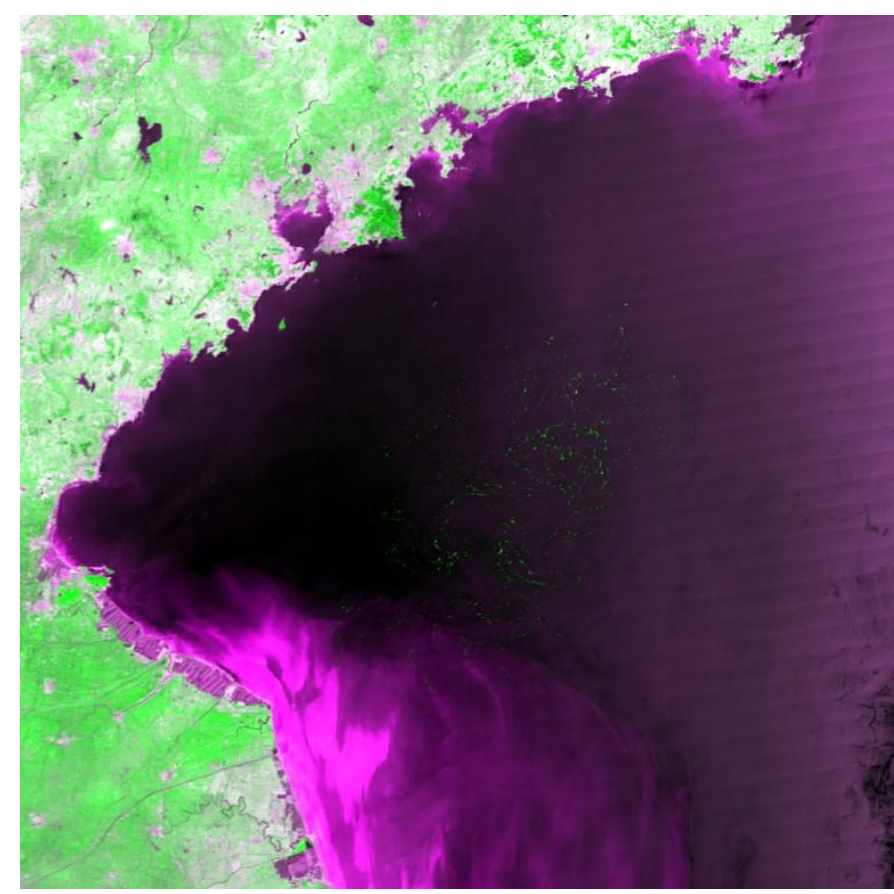

Fig.1 MODIS Aqua RGB (1, 2, 1 bands) image in the Yellow Sea acquired at 4:40 UTC on May 31, 2008.

Daily, weekly and monthly satellite wind data at $10 \mathrm{~m}$ above the sea surface are obtained from QuikSCAT data archives (http://www.ssmi.com/qscat/).

\section{METHODOLOGY}


We use an FAI (Floating Algae Index) method proposed by $\mathrm{Hu}{ }^{[6]}$ to observe the floating of $U$. prolifera from MODIS images. The method has been proved to be more effective in detecting floating macroalgae than other methods.

FAI is defined as ${ }^{[6]}$ :

$$
\begin{aligned}
F A I & =R_{(r c, N I R)}-R_{(r c, N I R)}{ }^{\prime} \\
R_{(r c, N I R)} & =R_{(r c, R E D)}+\left(R_{(r c, S W I R)}-R_{(r c, R E D)}\right) \times \frac{\left(\lambda_{N I R}-\lambda_{R E D}\right)}{\left(\lambda_{S W I R}-\lambda_{R E D}\right)}(1)
\end{aligned}
$$

where $R_{(r c, N I R)}$ is the sea surface reflectance at near infrared (NIR) band; $R_{(r c, N I R)}$ is the baseline reflectance in the NIR band derived from a linear interpolation between the reflectance at red and short-wave infrared (SWIR) bands, $R_{(r c, R E D)}$ and $R_{(r c, S W I R)}$, respectively. $\lambda_{R E D}, \lambda_{N I R}$ and $\lambda_{S W I R}$ are the wavelengths at red, NIR and SWIR, respectively. For MODIS, $\lambda_{\text {RED }}=645 \mathrm{~nm}, \lambda_{\text {NIR }}=859 \mathrm{~nm}, \lambda_{\text {SWIR }}=1240 \mathrm{~nm}$.

$\mathrm{FAI} \geq 0.2$ is assumed to correspond to $100 \%$ algae coverage and $\mathrm{FAI} \approx 0$ represents $0 \%$ algae coverage ${ }^{[7]}$.

\section{RESULTS AND DISCUSSION}

Fig. 2 are some examples of the FAI images of floating algae in the Yellow Sea derived from cloud-free MODIS imagery during May to July, 2008. The locations of $U$. Prolifera identified from FAI imagery during this period are shown in Fig. 3. From Figs. 2 and 3 we can see the evolution of the algae bloom. The U. Prolifera bloom first appeared in mid May near the coast of Lianyungang. The floating macroalgae moved northward into the middle of the Yellow Sea and grew rapidly, reaching a peak size at the end of May. They landed on the coast of Qingdao in late June. The algae then moved eastward in July and remained visible until early August.

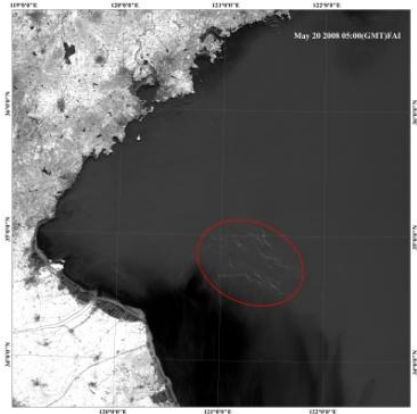

(a)

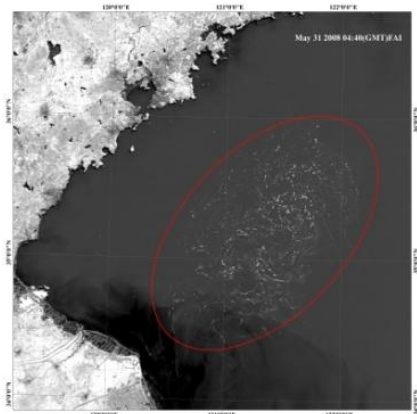

(c)

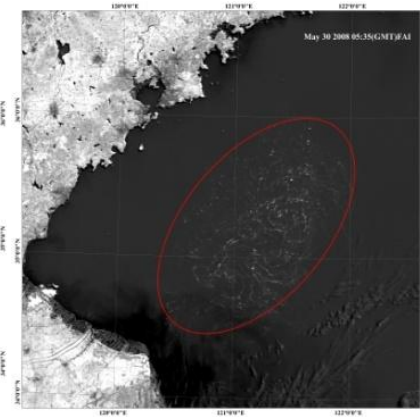

(b)

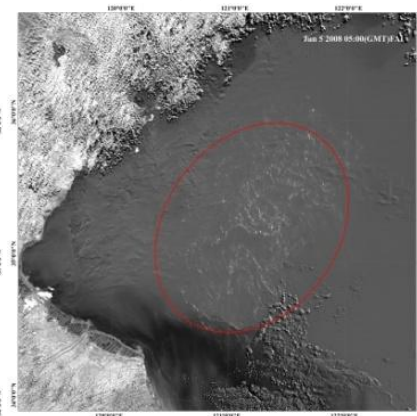

(d)

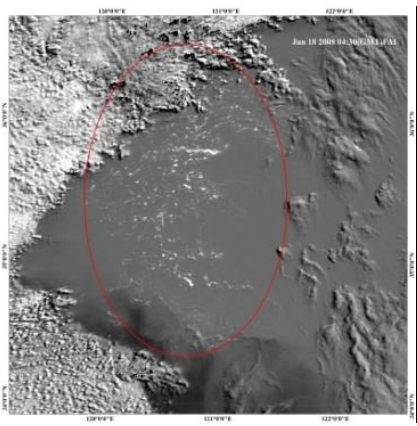

(e)

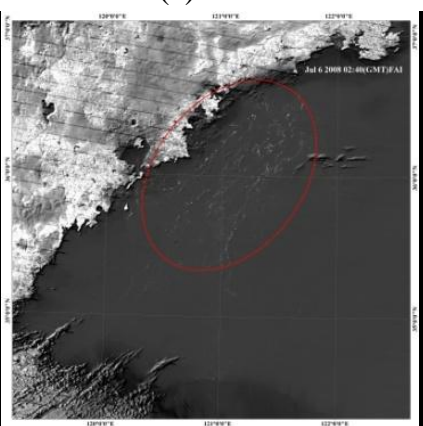

(g)

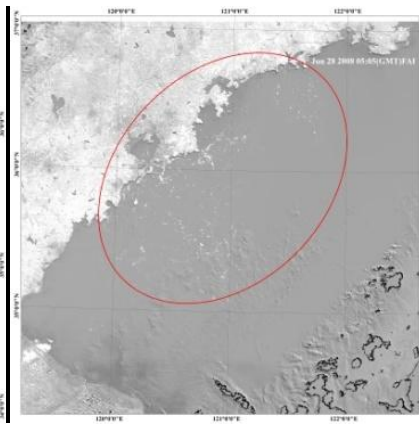

(f)

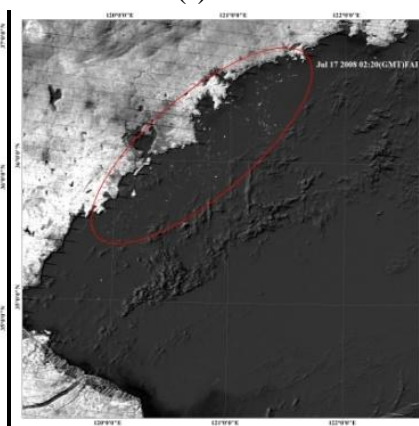

(h)
Fig. 2 FAI images of floating algae in summer 2008. Ellipses denote extent of the floating algae.

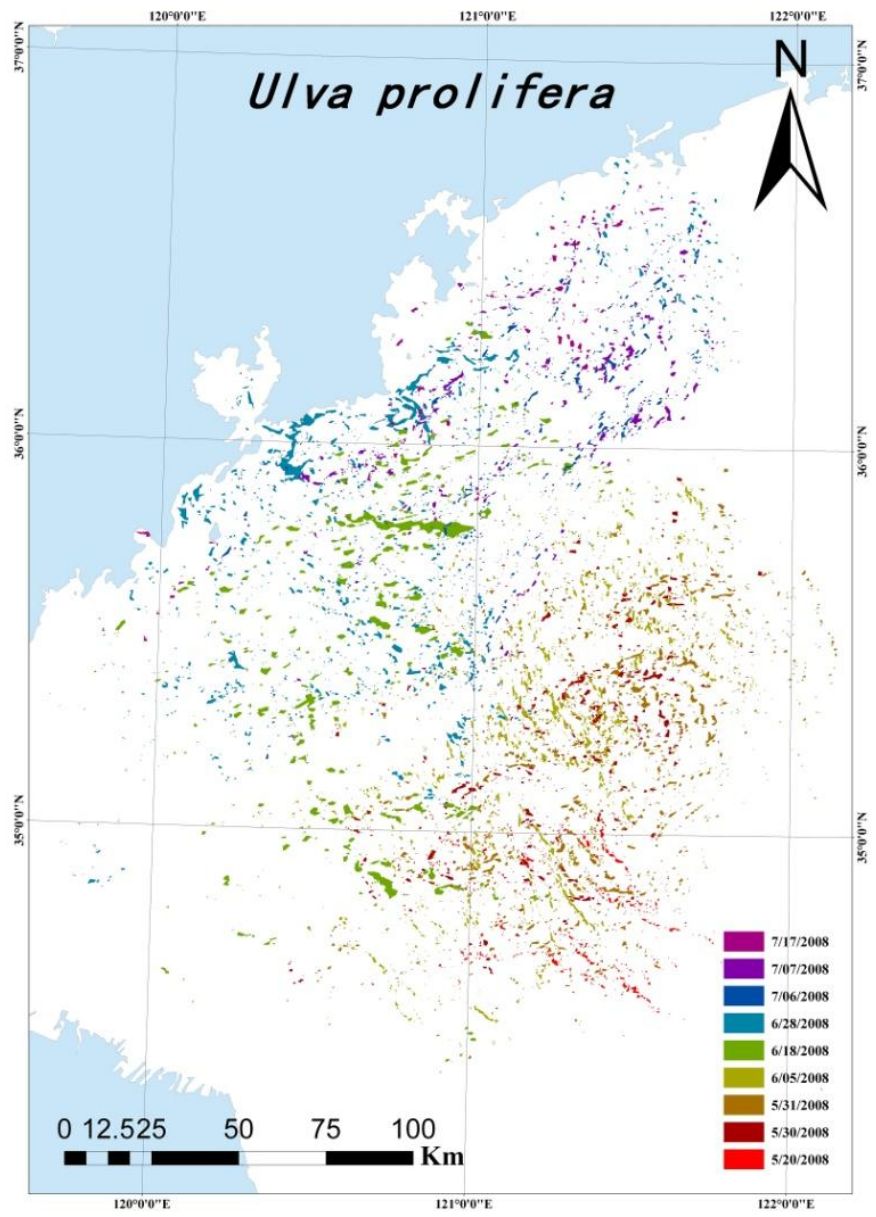

Fig.3 Location and distribution of Ulva prolifera identified from MODIS FAI imagery. 
The QuikSCAT surface winds in the Yellow Sea are shown in Fig. 4. Daily, weekly and monthly winds are all examined. Comparing the detected algae bloom (Figs. 2 and 3) with surface wind pattern, it is clearly seen that the algae slicks followed the northward wind in general. During May to July, the winds are light, lower than $8 \mathrm{~m} \mathrm{~s}^{-1}$. The wind directions are predominantly from the south or south-east, driving the surface ocean current northward or north-westward, which led to the north-westward floating of the $U$. Prolifera. In early July, the winds near the coast of Qingdao were from the south-west, moving the macroalgae to the north-east

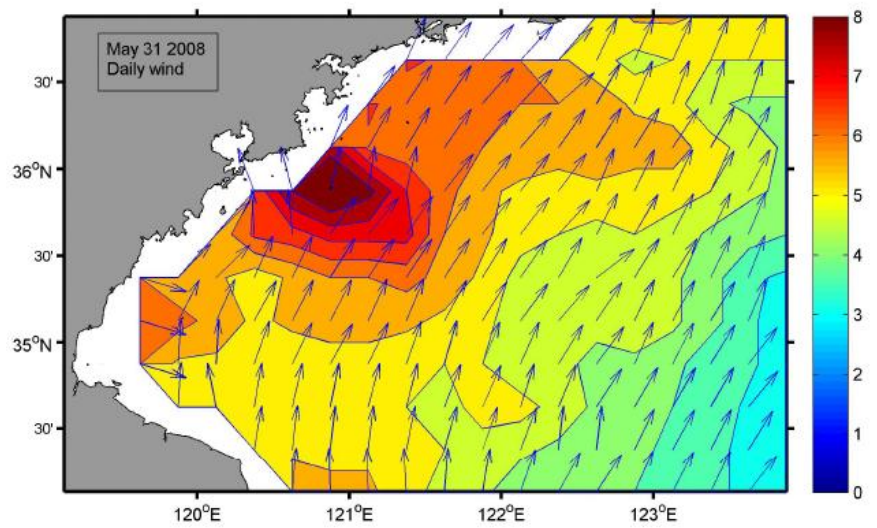

(a)

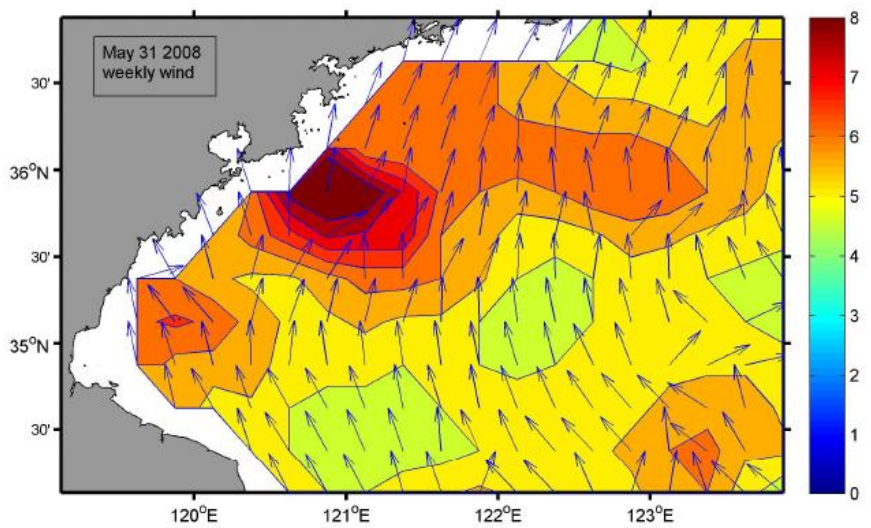

(b)

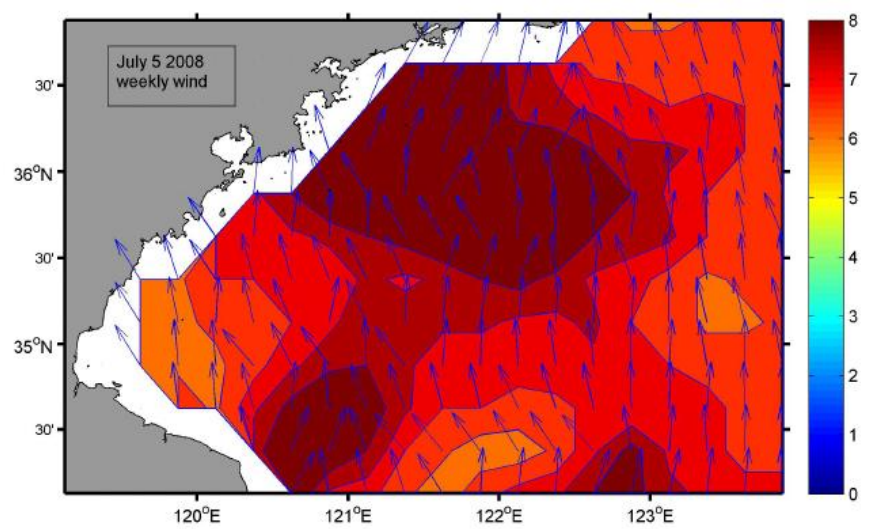

(c)

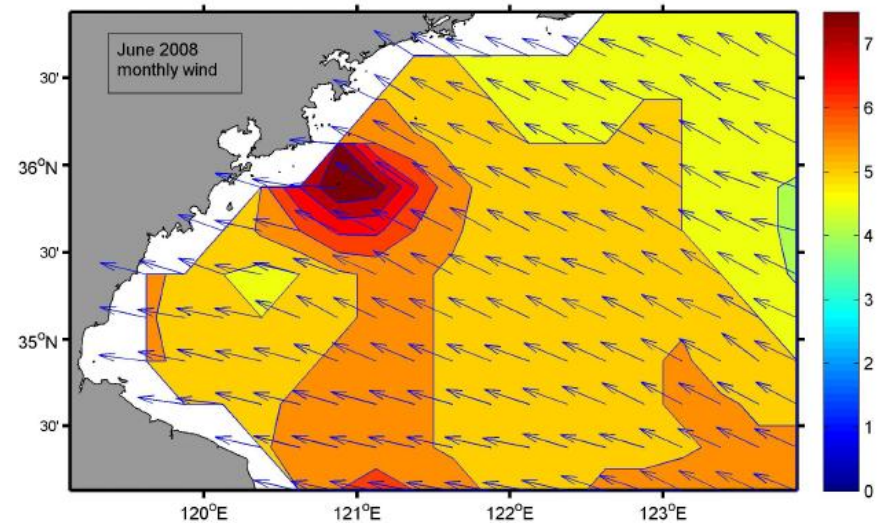

(d)

Fig. 4 Daily (a), Weekly (b and c) and Monthly (d) QuikSCAT surface wind speed and direction in the Yellow Sea.

\section{CONCLUSION}

Using satellite MODIS imagery, we investigated the occurrence and evolution of the $U$. Prolifera bloom in the Yellow Sea in summer of 2008. The location and extent of the floating macroalgae were detected with an FAI method. The results show the capability and effectiveness of satellite data to monitor the green tide.

By combining sea surface wind data from QuikSCAT, we found that there was a good agreement between the floating pattern of the $U$. Prolifera and the wind direction. This indicates that the winds played an important role on the movement of the floating algae in the Yellow Sea where the summer surface currents are primarily driven by wind.

\section{ACKNOWLEDGMENT}

This work was supported by the National Natural Science Foundation of China through grant 41006108, the Open Funds of Shandong Provincial Key Laboratory of Marine Ecology and Environment \& Disaster Prevention and Mitigation through grant 2011001, and the Key Laboratory of Ocean Circulation and Waves, Chinese Academy of Sciences through grant KLOCAW1203.

\section{REFERENCES}

C. $\mathrm{Hu}, \mathrm{D} . \mathrm{Li}, \mathrm{C}$. Chen, et al. On the recurrent Ulva prolifera blooms in the Yellow Sea and East China Sea. Journal of Geophysical Research: Oceans, 2010, 115, C05017.

J. K. Keesing, D. Y. Liu, P. Fearns, et al. Inter- and Intra- annual patterns of Ulva prolifera green tides in the Yellow Sea during 2007-2009, their origin and relationship to the expansion of coastal seaweed aquaculture in China. Marine Pollution Bulletin, 2011, 62(6): 1169-1182.

C. E. Naimie, C. A. Blain, D. R. Lynch, Seasonal mean circulation in the Yellow Sea-a model-generated climatology. Continental Shelf Research, 2001, 21(6): 667-695. 
W. E. Esaias, M. R. Abbott, I. Barton, et al. An overview of MODIS capabilities for ocean science observations. IEEE Transactions on Geoscience and Remote Sensing, 1998, 36: 1250-1265.

C. Hu, F. E. Muller-Karger, C. J. Taylor, et al. Red tide detection and tracing using MODIS fluorescence data: A regional example in SW Florida coastal waters. Remote Sensing of Environment, 2005, 97(3): 311-321.
C. $\mathrm{Hu}, \mathrm{A}$ novel ocean color index to detect floating algae in the global oceans. Remote Sensing of Environment, 2009, 113(10): 2118-2129.

C. $\mathrm{Hu}, \mathrm{Z}$. Lee, R. Ma, et al. Moderate Resolution Imaging Spectroradiometer (MODIS) observations of cyanobacteria blooms in Taihu Lake, China. Journal of Geophysical Research, 2010, 115, C04002. 